Revista de la red interuniversitaria de estudios sobre las literaturas rioplatenses contemporáneas en Francia

$13 \mid 2015$

Nuevas experiencias editoriales y literaturas

contemporáneas

\title{
Los espacios públicos de la literatura contemporánea
}

Lionel Ruffel

Traductor. Florencia Justo

(2) OpenEdition

Journals

Edición electrónica

URL: http://journals.openedition.org/lirico/2112

DOI: $10.4000 /$ lirico. 2112

ISSN: 2262-8339

Editor

Réseau interuniversitaire d'étude des littératures contemporaines du Río de la Plata

Referencia electrónica

Lionel Ruffel, «Los espacios públicos de la literatura contemporánea », Cuadernos LIRICO [En línea],

13 | 2015, Puesto en línea el 15 diciembre 2015, consultado el 21 abril 2019. URL : http://

journals.openedition.org/lirico/2112 ; DOI : 10.4000/lirico.2112

Este documento fue generado automáticamente el 21 abril 2019.

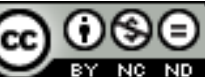

Cuadernos LIRICO está distribuido bajo una Licencia Creative Commons Atribución-NoComercialSinDerivar 4.0 Internacional. 


\title{
Los espacios públicos de la literatura contemporánea
}

\author{
Lionel Ruffel \\ Tradución : Florencia Justo
}

1 Existen muy pocas nociones realmente transhistóricas y realmente globales de manera transhistórica. Ninguna de las que suelo usar en mi profesión lo es. Literatura, autor, texto, obra, etc. son todas nociones fechadas y situadas. Por otra parte, existen pocas nociones que atraviesen esferas de existencia tan diversas (aunque desde luego conectadas) como la política, la cultura, la urbanización, la planificación territorial, la cuestión doméstica. El espacio público es una de ellas. Si bien no se puede decir que sea universal ni antropológicamente estructuradora, es una noción transhistórica, global, y atraviesa prácticamente todas las esferas de la existencia. Los últimos cincuenta años no han cesado de mostrar su importancia. Cincuenta, porque en 1962, Jürgen Habermas propuso una arqueología de la modernidad mediante la conceptualización del espacio público; también, porque desde hace cincuenta años todas las revoluciones, todas las conmociones políticas suponen la ocupación de espacios públicos, desde Tahrir, el parque Zuccotti o la Puerta del Sol hasta la plaza Maidán en Kiev. Porque no se nos deja de repetir que la red mundial es una nueva ágora, término cuya traducción moderna sería "espacio público" ; porque nuestro mundo hiperurbanizado implica la aparición de otros espacios además de los lugares privados: parques, plazas o, según la definición del antropólogo Marc Augé, no lugares (aeropuertos o centros comerciales) ; porque -y esto es sin duda lo que más nos interesa- una parte de la producción artística contemporánea (estoy pensando en esas artes que la modernidad no nos ha acostumbrado a ver como representaciones públicas, en particular la literatura y las artes plásticas) ocupa, en gran medida, los espacios públicos. Es el caso de las performances en el campo literario, o en el arte llamado a veces relacional y otras veces contextual.

2 Se me podría objetar que confundo dos cosas diferentes : el espacio público y la esfera pública. Es decir, por un lado, los espacios materiales sustraídos a lo privado y abiertos a la utilización por parte de uno o más públicos, y por otro lado, la arena inmaterial de los debates acerca de la cosa pública. Para decirlo sumariamente, se me objetará que 
confundo la plaza con el ágora. Pero esta confusión es totalmente voluntaria, ya que la distinción radical entre ambas nociones proviene de un modelo ideal heredado de la modernidad (y descrito por Habermas) que nos impide pensar aquello que, en última instancia, me propongo analizar : el vínculo entre la literatura contemporánea y diversos espacios públicos. El uso del plural es significativo porque implica el abandono de la distinción entre una magnífica y admirable esfera pública y los despreciables espacios públicos, lo que permite concebir una pluralidad de espacios públicos en oposición.

\section{El imaginario literario del espacio público}

Quiérase o no, resulta hoy difícil hablar del espacio público sin hacer referencia a la teoría de Jürgen Habermas. En tanto es una de las teorías que han transformado profundamente las representaciones contemporáneas, es necesario dar cuenta de ella. Como teórico de la literatura contemporánea, debo reconocer lo atractivos que pueden ser sus postulados, ya que, efectivamente, sitúan la literatura contemporánea, y la contemporaneidad, en el centro de su sistema.

El objetivo del libro de Habermas es analizar el surgimiento de una nueva concepción política en los cimientos de las sociedades europeas modernas. Para ello, el teórico alemán establece una distinción entre el dominio público (el del Estado o el del poder) y el dominio privado (el de los individuos). En los regímenes absolutistas premodernos, el dominio público en su totalidad está en manos de una casta cuyo dominio privado es también público. Es lo que refleja la famosa frase de Luis XIV: “iEl Estado soy yo!”, mientras que el resto de la población se entrega a una existencia exclusivamente privada ; privada, en particular, de una participación en el dominio público. Según Habermas, en Alemania, Inglaterra y Francia, cuando se desarrolla la sociedad burguesa, el dominio privado se escinde en una esfera privada y una "esfera pública política", gracias a la cual las personas privadas se reúnen para debatir temas de interés público o de interés común.

Para Habermas, la literatura desempeña un papel determinante en la constitución de esta esfera pública. Es debido a la apertura de un espacio de debate sobre las obras de arte contemporáneas, y en especial sobre las obras literarias, que comienzan a delinearse, en el siglo XVIII, las premisas de una esfera pública política. El público urbano sustituye al público de la Corte, fundamentalmente mediante el desarrollo de salones y cafés. Herederos de aquella, estos "promueven" una especie de igualdad entre gente culta, poniendo en el mismo nivel a la sociedad aristocrática y a ciertos intelectuales burgueses (43). No cabe duda de que se trata de una construcción idealizada en la que la "gente" son hombres "burgueses", y en la que la igualdad se ejerce en el seno de una nueva clase dominante. Habermas describe, más que una realidad, la arqueología de una ideología que se impuso a la realidad. Y él la recibe como una realidad y la transmite como tal.

6 Sin embargo, esta ideología que se impuso a la realidad nos dice que es el debate literario el que preexiste al debate político y, por lo tanto, a la esfera pública. Porque ese foro es solo una etapa de un proceso más amplio, que es el de la extensión de esta ágora a la sociedad, por intermedio del mercado. Este modelo nuclear, según Habermas, no puede cerrarse sobre sí mismo, ya que el arte se ha vuelto una mercancía; está destinado a extenderse para constituir una verdadera esfera pública que ya no puede ser contenida en los espacios públicos. Se trata de la noción de "gran público", que no hay que confundir con la de población de un país o, peor aún, con el pueblo. El gran público recibe su educación de la escuela y, sobre todo, de la crítica que se despliega en los periódicos, cuyo 
poderío surge en esa época. El encuentro físico desaparece, el "público que lee y comenta esos artículos se encuentra a sí mismo como tema de sus propias discusiones" (53). Existe entonces un encuentro superior, en una esfera pública inmaterial.

7 El influyente modelo analizado por Habermas, que hemos heredado, le da a la literatura no solo una nueva definición sino también su nombre : la literatura. Este modelo otorga a la literatura el más alto valor solamente si ésta abandona un espacio físico de encuentro, el cual es doblemente desvalorizado. Al principio, como forma absolutista inherente a la Corte; luego, como transición de los Salones hacia una verdadera esfera pública democrática. El público de la literatura se convierte en una de esas abstracciones, en relación con esa otra abstracción que es el público-pueblo de la democracia. El público de los espectáculos (corporal, concreto, compuesto por individuos, a menudo inquieto, vocinglero, maloliente y potencialmente peligroso) constituye su antimodelo. En lo sucesivo, toda nuestra representación de lo literario, en tanto modelo de las democracias modernas, se fundará en esta distinción. Del mismo modo que la modernidad en su conjunto.

\section{Conflictividad de la arena pública}

8 Ahora bien, este modelo ha sido sumamente cuestionado, principalmente por la teoría feminista, y en particular por un texto fundamental para nuestra época : "Rethinking the Public Sphere", de Nancy Fraser. Según esta autora, el "problema no reside solamente en que Habermas idealice la esfera pública liberal, sino también en que olvide estudiar otras esferas públicas rivales, no liberales y no burguesas » (132). Fraser recuerda así que esta esfera pública idealizada se basaba en un gran número de exclusiones, la más importante de las cuales era, desde luego, el género, exclusión que llevaba aparejada otra, fundada en criterios de propiedad y en criterios raciales. Desigualdades de género, de clase y étnicas. De modo muy significativo, Fraser recuerda que una de las cuestiones en juego era la eliminación de la cultura de salón -cultura literaria si las hay-, sumamente feminizada. Una cultura literaria que era, por lo demás, el parangón del sistema en red, de esas multitudes animales a las que se opone la correcta comunidad de los lectores. Podemos suponer que la ideología de la literatura que excluye toda práctica in praesentia es exactamente el corolario de la ideología política de la unidad abstracta de la esfera pública. No obstante, "casi en la misma época, surge una multiplicidad de contra-públicos rivales, incluyendo públicos nacionalistas, públicos campesinos populares, públicos de mujeres de la élite y públicos de clase obrera" (133). Sin embargo, según la lectura que Habermas hace de la modernidad, una lectura que nos resulta completamente familiar, esos contra-públicos rivales, que desarrollan otra concepción del modo de compartir el tiempo, no han existido. Sencillamente, porque se suponía que la esfera pública idealizada debía acoger a todo el mundo bajo una apariencia de igualdad. Solo que, según Fraser, la apariencia de igualdad no existe. Hay igualdad o no la hay. La apariencia de igualdad es una herramienta para que los dominados acepten nuevas formas de desigualdad y una nueva forma de consentimiento, según la cual "una esfera pública común a todos es un estado positivo y deseable, mientras que la proliferación de una multiplicidad de públicos aleja de la democracia, en lugar de acercar a ella" (138). La teoría de Nancy Fraser es exactamente inversa porque demuestra que, en cualquier tipo de sociedad, la aparición y el desarrollo de lo que ella llama (retomando en especial a Spivak) "contra-públicos subalternos" se acerca más al ideal de paridad de participación de todos en el debate y las 
deliberaciones públicas que el ideal de una esfera pública única. En este punto, cabe hacer una distinción entre las comunidades y los públicos : estos últimos son performativos y temporarios, y es posible pertenecer a varios de ellos simultáneamente. Esta proposición política, en la que Fraser se encuentra con Spivak (en lo que toca a los contra-públicos subalternos) y con Judith Butler (en lo que se refiere a la performatividad) es la proposición esencial de los mundos contemporáneos; lo es desde el punto de vista político, desde el punto de vista cultural, y también en el plano de las subjetividades o en el de los colectivos.

9 La idealización de la esfera pública implica una valorización del silencio, lo contrario del bullicio. Esa idealización, opuesta a mi perspectiva sobre lo contemporáneo, exige silenciar las desigualdades reales en favor de una igualdad de principio (Ruffel 2016). Si retomamos el lazo orgánico entre una idealización de la esfera pública como esfera literaria, notamos que, efectivamente, la idea de literatura que se impuso durante la modernidad está estrechamente vinculada al silencio. Y se opone, con la misma fuerza, al bullicio. La historia literaria nos muestra así hasta qué punto la historia de la poesía, por ejemplo, es un lento desasirse de la música externa en favor de la música interna ; hasta qué punto el texto dramático ideal toma la forma del teatro de sillón; hasta qué punto la novela no necesita ser leída en voz alta y, por esta razón, domina a los otros géneros. No es que la esfera pública idealizada condene "las artes del espectáculo"; al contrario, las disciplina con la idea de catarsis, esa regulación de las malas pasiones. La literatura, al no poder ser incluida en este marco conceptual, al pertenecer al marco conceptual de la comunicación silenciosa in absentia, no debía ser ni espacial, ni pública, ni oral.

Ahora bien, así como existen contra-públicos subalternos que se oponen a la esfera pública idealizada, existen contra-públicos subalternos que se oponen al ideal de la literatura silenciosa, próximos al modelo contra-ideal del bullicio. Esos contra-públicos subalternos literarios no son necesariamente la encarnación de contra-públicos subalternos "sociopolíticos", sino la expresión de una práctica de la literatura que no se construye a partir de la triple exclusión del espacio, el cuerpo y el sonido. Numerosos estudios históricos, como los de Richard Hoggart en Gran Bretaña, de Jacques Rancière en Francia, de Lawrence Levine en Estados Unidos han mostrado, sin embargo, hasta qué punto ambos públicos están vinculados. Hasta qué punto los obreros y los "pobres" han tendido históricamente a una práctica performativa de la literatura. Varios estudios históricos han mostrado hasta qué punto el ideal de literatura era hegemónico pero no total. La performance poética y las lecturas públicas siempre han acompañado a la difusión escrita ; simplemente, han sido silenciadas por la historiografía canónica.

Quisiera postular, entonces, que esos momentos de inscripción de lo literario en los espacios públicos (lecturas, performances, exposiciones, etc.) pertenecen a una lógica propia de los contra-públicos subalternos. La mejor prueba es la reacción que a veces suscitan. Se acusa a estas formas o bien de no ser literatura, sino simplemente ruido o balbuceo, o bien de ser en cierto modo sectarias. No obstante, la acusación de sectarismo proviene de quienes han idealizado la esfera pública y no se avienen a reconocer que existe una multiplicidad de espacios públicos, temporarios o coexistentes.

\section{El momento contemporáneo de las literaturas}

Plantearé, al contrario, que esta multiplicidad de espacios públicos es un rasgo característico del momento contemporáneo de la literatura, tal como la esfera pública de 
la Literatura era un rasgo característico de su representación moderna. Si bien esos espacios públicos siempre han existido, aunque silenciados, nunca han sido tan numerosos y visibles. No solo se han multiplicado, sino que se han diversificado enormemente, hasta el punto de que la literatura es hoy en día, en su mayor parte, una arena conflictiva compuesta, por un lado, por una esfera pública hegemónica fundada en lo impreso y, por otro lado, por una multiplicidad de espacios públicos contrahegemónicos vinculados a una "literatura ruidosa" (una literatura expuesta, actuada, in situ, en soportes variados), con numerosas conexiones entre ellos.

Por una parte, cabe pensar que los contra-públicos subalternos, que consideran el triunfo de la Literatura como el de la clase burguesa masculina occidental, han hallado en las formas de la literatura ruidosa un modo de llevar a cabo, en el plano literario, una lucha específicamente política. La carrera del cantante estadounidense Gil Scott Heron puede ser interpretada en este sentido : en sus comienzos escribe dos novelas (ver Scott Heron 1998) y luego "inventa" ese género particular de la poesía que es el spoken-word o la canción-poema. El desarrollo de la literatura ruidosa proviene, pues, de las exclusiones fundadas en el género, la clase, el origen étnico. Es más que una convergencia de luchas. Es la no reproducción de los mecanismos de dominación creados por la modernidad. A partir de ahí se podrían reconsiderar ciertas tradiciones literarias ajenas a la "Literatura", en particular al mundo "occidental".

Otro enfoque contra-hegemónico que también ha sido desarrollado en el interior del campo literario reside en la distinción entre publicación de lo literario en la edición y publicación de lo literario fuera de la edición. Aunque es difícil presentar un análisis sistemático del campo editorial de manera global, es posible esbozar algunos de sus rasgos. Desde el punto de vista estructural, el mercado mundial de la edición responde a las mismas características que los mercados ultracompetitivos, vale decir que responde al modelo económico del "oligopolio con franjas" (Sapiro 2009, Schiffrin 2000, Benhamou 2003). Este término, procedente del vocabulario económico, refiere a la concentración cada vez mayor de la producción en unos pocos grandes grupos que se internacionalizan, y a una atomización de la pequeña producción, que se vuelve restringida (esto es válido a nivel nacional e internacional). Así, toda la parte media de la producción va desapareciendo gradualmente. Los efectos estéticos de normalización son tales que una parte de los creadores actuales pone cada vez más en tela de juicio la publicación de literatura impresa. Y de esta manera, el capital simbólico de la publicación mediante la literatura-texto es también profundamente cuestionado. Los ejemplos nos demuestran que una lectura en un teatro repleto puede tener más valor que una publicación restringida.

Recientemente, Philippe Vasset, autor del notable Un livre blanc -libro de indagación sobre las zonas blancas ("vacías") de los mapas oficiales de la Isla de Francia-, aludiendo a las expansiones que dio a su libro (visitas con lectores a esas zonas blancas, por ejemplo), teorizó de manera radical y provocadora la condición literaria contemporánea :

El entusiasmo de los escritores contemporáneos por las lecturas públicas y la exhibición o la realización de obras sonoras no es tanto consecuencia de la conquista de nuevos territorios fuera del texto como de la modificación del equilibrio interno del libro mismo, que ya no se concibe como un objeto total, cerrado sobre su intemporal perfección, sino como una nube de potencialidades.

El horizonte de la literatura contemporánea es el libro de cocina. Tal vez el manual de bricolaje.

Producido por millares cada año, eliminado de los estantes de las bibliotecas en 
pocas semanas, leído y comentado en círculos cada vez más restringidos, el libro se volvió un objeto precario, frágil, casi insignificante. ¿Cuántos escritores contemporáneos han visto agotarse sus obras, de tiradas cortas, en algunos años, y luego desaparecer, ya que sus editores consideran que no vale la pena reimprimirlas ? ¿Cuántos han debido crearse sus propias librerías distribuyendo a pedido archivos de textos escaneados y posteando en sus sitios web sus publicaciones más raras, o incluso toda su producción?

Esta fragilización de lo impreso, de sus circuitos de distribución y de fabricación, y el envejecimiento paulatino de los lectores de libros "tradicionales" (vale decir en papel, en gran formato y vendidos en librerías) incitan cada vez más a los autores jóvenes a dejar de considerar el texto como una totalidad acabada, inmutable y cerrada sobre sí misma, y a empezar a verlo, al contrario, como una especie de partitura, un generador de eventos, un catálogo de ideas y de acciones que la versión publicada del texto solo realiza parcialmente y que deberán ser desarrolladas en otra parte, por el autor o incluso el lector. Quien ha llevado más lejos esta práctica es Edouard Levé con Euvres (París, P.O.L, 2002) : una descripción de quinientos proyectos, de los cuales solo una pequeña parte había sido realizada en el momento de la redacción.

Las lecturas-performance y las realizaciones gráficas y sonoras no se agregan al texto, sino que más bien prolongan su ejecución. Forman parte del programa de escritura original. [De manera más trivial, el libro se usa cada vez más para las lecturas públicas.] (Rosenthal y Ruffel 2010).

16 Este cuestionamiento de los soportes impresos en favor de otros soportes no es ajeno a la normatividad inherente al mundo de la edición, la cual se ve acentuada en el contexto neoliberal, en el que se reduce de manera evidente la variedad formal que se propone para la publicación. Poco a poco, un océano infranqueable ha ido separando la gran edición comercial, especializada en la narración (ficcional o no), de la pequeña edición o de la microedición, que multiplica los títulos, las estructuras y los géneros. Estos parámetros han modificado considerablemente la relación que los escritores establecen con el libro y la publicación. Si proliferan las performances, las lecturas públicas, las grabaciones sonoras o las inscripciones escritas directamente sobre el territorio (afiches, esténciles, etc.), es porque el libro como objeto principal de transmisión ha sido objeto de críticas que, en ciertos casos, provienen de los escritores mismos. Se llega de este modo a una idea plural de la publicación - de las publicaciones-opuesta a una única concreción en el libro. El mismo Philippe Vasset describe la dimensión activista de esta concepción :

Actuar el texto propio, recitarlo en público, permite salir de la economía de lo impreso y dejar de ser el representante comercial de uno mismo. En el campo literario, el rol del escritor es ante todo vender su libro : lo dedica (a los lectores que lo compran), hace su promoción (en los medios de comunicación más afines a los lectores que lo compran), y gana premios (que diferenciarán su libro de otros en las vidrieras).

Liberado del objeto-libro, el escritor ya no está sometido a esas obligaciones comerciales y puede, por fin, producir algo gratuito, no comercial. Su discurso, puramente suntuario, limitado en el tiempo y el espacio, deja de tener precio y se convierte en un don total : ya no hay nada para vender. (Vasset, 32)

17 La importancia de estas formas de publicación se vuelve todavía más patente cuando se considera que, del otro lado, el aspecto cultural de las prácticas sociales y el giro relacional que han tomado las políticas públicas incitan a explorar y conquistar nuevos campos. En estas categorías se puede incluir un conjunto de prácticas muy heterogéneo y a veces contradictorio. Pondré algunos ejemplos. Actualmente, la mayor parte de los lugares de exposición ofrece una programación cultural para lo que hoy se denomina "públicos". Esta programación, para no reproducir las especificidades de otros lugares 
dedicados a la difusión de obras frente a un público (como el teatro, el cine o la sala de conciertos), se abre a otras propuestas que constituyen un ámbito de exploración para la literatura no impresa. El fenómeno es tan corriente que solo mencionaré uno de los ejemplos más espectaculares entre los recientes : la creación, en 2013, del estatuto de "Poet Laureate" en el MoMA, otorgado en su primera edición al poeta underground Kenneth Goldsmith, quien propuso en esa ocasión una serie de performances intituladas "Guerrilla Readings", en las cuales invitaba a un conjunto de autores (de Vanessa Place a Charles Bernstein) que participan en el movimiento de inserción de la literatura en los espacios públicos.

Otro ejemplo, que se superpone al primero. Las políticas públicas se fundan desde hace tiempo en la idea de cultura como vector de cohesión social. Durante un largo período, prevaleció el enfoque monumental y suntuario, supuestamente portador de sentido para la comunidad. Actualmente, al contrario, se tiende hacia enfoques micropolíticos que favorecen la inscripción de los artistas, y por qué no de los escritores, en un determinado tejido social. Es lo que David Ruffel concibe como el momento relacional de las literaturas en el espacio público :

A diferencia de la literatura expuesta y llevada a la performance, las prácticas "relacionales" no consisten en ocupar los lugares destinados al arte, sino el campo social. No se trata tanto de ampliar el territorio de la literatura como de interrogarse sobre su naturaleza, experimentar los vínculos que teje con la sociedad, los lectores, las redes, y repensar el estatuto de creador, así como la naturaleza de la obra literaria a través de las relaciones establecidas durante su elaboración y recepción. Ese momento "social" de la literatura contextual es mucho más reciente que su momento "estético" (67). ${ }^{1}$

19 Centrándose en el ámbito francés, el autor estudia residencias de escritores (fundamentalmente las de la poeta Sonia Chiambretto) y talleres de escritura como los de François Bon, pero también experiencias más sorprendentes, como el trabajo del teórico/ curador/escritor Jean-Yves Jouannais, quien, tras destacarse por sus trabajos teóricos ( Artistes sans œuvres, L'Idiotie), se embarcó en un proyecto excepcional : una Enciclopedia de las guerras oral, escénica y no destinada a la publicación. El autor cuenta el origen del proyecto en los siguientes términos: "el libro no es más que un episodio formal que ofrece una gratificación. Pero podemos ahorrárnoslo. Podemos ahorrarnos la publicación y la escritura misma. Me intriga saber hasta dónde podemos reducir la experiencia de la escritura sin que deje de haber literatura." (Rosenthal y Ruffel 2010)

Tercer ejemplo : la institucionalización de la creación literaria en espacios de transmisión pedagógica como la escuela y la universidad. El profesor-escritor cobra una remuneración menor por lo que publica que por lo que enseña (pues si hemos hablado de capital simbólico, no hay que desdeñar el capital económico). En el marco del oligopolio con franjas, la literatura impresa raramente permite al autor ganarse la vida, como sí puede permitírselo la publicación de otro tipo. Se gana, por así decirlo, salvo en pocas excepciones, mucho más dinero con las residencias, becas y, sobre todo, con la enseñanza de la escritura, que con la venta de libros. Según uno de los más destacados estudiosos de este fenómeno, es posible que estemos viviendo un momento histórico de reconfiguración del campo literario (Mc Gurl 2009). Según este investigador, la "era del programa" ("programa" en el sentido de los programas de enseñanza de escritura creativa) sería un nuevo modelo que no respondería ni al concepto de heteronomía ni al de autonomía (según la terminología de Pierre Bourdieu); un modelo que no sería el del mecenazgo premoderno, ni tampoco el de la economía moderna. Actualmente coexistirían, 
principalmente en Estados Unidos, un sistema literario clásicamente capitalista, y otro sistema que se ha desarrollado en las universidades, pero que por sus dimensiones, por su institucionalización, constituye el principal fenómeno literario de la posguerra. Un fenómeno, para bien o para mal, fundado en la presencia de la literatura en esos espacios públicos que son los lugares de transmisión, y donde la publicación es por naturaleza plural (los libros constituyen una mínima parte de ella). En este sistema, la "literatura ruidosa" se ha impuesto claramente a la "Literatura".

Un último fenómeno : el reino de lo escrito nunca ha estado más extendido ; nunca la idea de publicación ha sido tan plural. No pasa un día sin que una gran parte de la humanidad publique uno o varios textos : en un blog, en una red social o en otro medio. Publicar ya no significa en absoluto participar en la maravillosa y abstracta esfera pública habermasiana. Más bien al contrario, muy a menudo lo que se busca es multiplicar las inscripciones en diversos espacios públicos. Cabe pensar, por ejemplo, en el enorme continente escriturario de las fan fictions, del que no nos interesa analizar el "valor" literario, sino destacar que funciona con protocolos editoriales sumamente sofisticados e inventivos, mediante los cuales cientos de miles de personas participan en algo que se puede denominar "escritura".

22 Así pues, lo que caracteriza a nuestra época es el fin de la representación única de la literatura en su relación con la cosa impresa y con una esfera pública idealizada. Una nueva representación surge: la de una arena literaria en mayor o menor grado conflictiva, en la que la esfera pública dialoga con una multiplicidad de espacios públicos, donde se desarrollan las literaturas ruidosas. La "Literatura" ya no es más que una de las actualizaciones posibles de lo literario y de la publicación.

\section{Hacia un imaginario de la publicación}

Los ejemplos citados no agotan las profundas transformaciones que atraviesan lo literario desde hace unos treinta años y nos obligan a cambiar de imaginario. La imagen de un autor único, recluido en su estudio, en relación directa con su editor y los actores que componen el campo (críticos, jurados literarios, etc.), que se dirige mediante el soporte del libro, in absentia, a un público masificado y anónimo, que forma parte de una esfera pública idealizada, modelo de las democracias modernas, corresponde muy poco a la realidad de lo literario hoy en día.

Esa imagen no corresponde a las múltiples prácticas literarias que se han desarrollado de manera exponencial, y que implican no solo nuevas estéticas, sino también una nueva economía que no se basa únicamente en los derechos de autor y la venta de libros. Tampoco corresponde a la nueva sociabilidad literaria fundada en la visibilidad. Desde las dedicatorias en librerías o las lecturas públicas hasta el desarrollo masivo y sin precedentes de los festivales literarios, nos encontramos ante una transformación de la presencia social de los autores. Aquella imagen tampoco encaja con el ingreso masivo de la literatura contemporánea en la institución escolar y universitaria, que reconfigura espacios, objetivos, modos de consagración. No corresponde a la transformación de la economía de la cultura en la época digital, la cual perturba el circuito, otrora bien trazado, que iba del autor al lector gracias al editor. Un circuito que se encarnaba en un objeto -el libro- y que transmitía cierta idea de la literatura. No se corresponde tampoco con las condiciones técnicas de la producción textual (procesadores de texto, programas de diagramación y de publicación), que han unificado las herramientas de producción, 
publicación, difusión y recepción, haciendo permeables las fronteras entre dichos polos. No se corresponde con el ámbito mediático y cultural contemporáneo, que ya no distingue, por un lado, el gran Arte, y por el otro, las prácticas culturales. Así, lo literario se concibe cada vez menos como una excepcionalidad frente a otras excepcionalidades (la artística o la religiosa) y se manifiesta como un objeto de comunicación social dentro de un conjunto de comunicaciones sociales. No corresponde a la extraordinaria masificación y diversificación que desde hace medio siglo caracterizan a la producción literaria, la cual ya no obedece al imaginario de la rareza. Y cada vez corresponde menos al modelo hegemónico euro-estadounidense, si tomamos en cuenta la diversidad de representaciones y las numerosas traducciones impulsadas por la globalización y las contra-escrituras minoritarias.

Si estas transformaciones tienen algo en común, es el pasar de una representación, y por tanto, de un imaginario de lo literario centrado en un objeto-soporte -el libro- a un imaginario de lo literario centrado en una acción y una práctica : la publicación. Publicar recobra su sentido original: hacer público, pasar de la expresión privada con interlocutores precisos a la expresión para públicos cada vez más diversos. La publicación de la literatura, históricamente, no se limita a los libros. Los públicos de la literatura no se limitan a los lectores. Existen tantas literaturas como posibilidades de publicación : libros, performances, lecturas, salones, grupos, espacios virtuales. Cada una de estas literaturas crea un espacio público específico. Por otra parte, esta era de la publicación supera ampliamente el marco de la literatura. La exposición y la performance (en las artes visuales y las artes escénicas) son también modos específicos de publicación, que se convierte en el gran concepto transversal que permite pensar las expresiones artísticas y culturales. Más allá de las prácticas artísticas, el concepto de publicación tiene consecuencias políticas. Si recordamos que Jürgen Habermas había hecho de la comunicación literaria mediante el libro el modelo idealizado de una sociedad democrática en camino hacia la racionalidad, cabe preguntarse qué imaginario político produce la pluralización de la idea de publicación. Por último, si tenemos en cuenta los debates acerca de la confidencialidad y la vida privada en la sociedad de la información, podemos concluir que la publicación es uno de los conceptos fundamentales de lo contemporáneo.

\section{BIBLIOGRAFÍA}

Bibliografía

Benhamou, Françoise. L'Économie de la culture. París : La Découverte, col. « Repères, 192 », 2003.

Bourdieu, Pierre. Les Règles de l'art : genèse et structure du champ littéraire. París : Seuil, 1992.

Fraser, Nancy. « Repenser la sphère publique. Une contribution à la critique de la démocratie telle qu'elle existe réellement ». Traducido del inglés por Muriel Valenta, Hermès, n 31, 2001 [1992]. 
Habermas, Jürgen. The Structural Transformation of the Public Sphere, An Inquiry into a Category of Bourgeois Society. Traducido del alemán por Thomas Burger con la asistencia de Frederick Lawrence, Cambridge (Mass.) : The MIT Press, 1992.

Hoggart, Richard. The Uses of Literacy : Aspects of Working Class Life. Londres : Chatto and Windus, 1957.

Jouannais, Jean-Yves. Artistes sans œuvres - I would prefer not to, París : Hazan, 1997.

Jouannais, Jean-Yves. L'idiotie. Art. vie. politique - méthode, París : éditions Beaux-Arts Magazine livres, 2003.

Levine, Lawrence. Highbrow/Lowbrow : The Emergence of Cultural Hierarchy in America. Cambridge : Harvard University Press, 1990.

McGurl, Mark. The Program Era. Postwar Fiction and the Rise of Creative Writing. Cambridge (Mass.) Londres : Harvard University Press, 2009.

Rancière, Jacques. La Nuit des prolétaires : Archives du rêve ouvrier. París : Fayard, 1981.

Rosenthal, Olivia y Ruffel, Lionel (ed.). « Entretien avec Jean-Yves Jouannais », en La Littérature exposée, les écritures contemporaines hors du livre. Número especial de Littérature. $\mathrm{n}^{\circ} 160$ (2010). París : Armand Colin, p. 14.

Rosenthal, Olivia y Ruffel, Lionel (ed.). « Entretien avec Philippe Vasset », en La littérature exposée : les écritures contemporaines hors du livre. Número especial de Littérature. $\mathrm{n}^{\circ} 160$ (2010). París : Armand Colin, p. 30-31.

Ruffel, David. « Une littérature contextuelle », en Rosenthal, Olivia y Ruffel, Lionel (ed.), La Littérature exposée, les écritures contemporaines hors du livre. Número especial de Littérature. $\mathrm{n}^{\circ} 160$ (2010). París : Armand Colin.

Ruffel, Lionel. Brouhaha, les mondes du contemporain. París-Lagrasse : Verdier, 2016.

Sapiro, Gisèle, «Introduction », en Sapiro, Gisèle (dir.). Les Contradictions de la globalisation éditoriale. París : Nouveau monde éditions, 2009.

Schiffrin, André. The Business of Books: How the International Conglomerates Took Over Publishing and Changed the Way We Read. Londres - New York : Verso, 2000.

Scott Heron, Gil. Le Vautour. Traducido del inglés por Jean-François Ménard. París : éditions de l’Olivier, 1998 [1970].

Vasset, Philippe. Un livre blanc. París : Fayard, 2007.

\section{NOTAS}

1. Remito al artículo completo, que se basa en numerosos ejemplos y, en verdad, hace emerger un nuevo corpus literario. 


\section{RESÚMENES}

Este artículo propone una crítica de la noción habermasiana de esfera pública ; esta, desde sus orígenes, se encuentra estrechamente ligada a la literatura. La esfera pública es descrita como una idealización en la cual el público de la literatura es concebido a partir de una triple supresión (el cuerpo, el espacio y el sonido). Esta representación no describe correctamente las prácticas contemporáneas, entre las cuales las performances literarias, las lecturas públicas y las publicaciones fuera del libro se encuentran cada vez más en el centro de la producción.

Cet article propose une critique de la notion habermasienne de "sphère publique ", une notion étroitement liée, depuis ses origines, à la littérature. La sphère publique est décrite comme une idéalisation dans laquelle le public de la littérature est conçu à partir d'une triple suppression (celle du corps, de l'espace et du son). Cette représentation ne décrit pas correctement les pratiques contemporaines, parmi lesquelles les performances littéraires, les lectures publiques et les publications hors du livre se trouvent de plus en plus au centre de la production.

This article aims at criticizing Habermas' notion of "public sphere", a concept which, since its origins, has been closely linked with literature. The public sphere is described as an idealization in which the public of literature is defined as the result of a triple suppression (that of body, sound, and space). This representation does not describe accurately the contemporary practices, among which literary performances, public readings and non-print publications are increasingly taking centre stage.

\section{ÍNDICE}

Palabras claves: esfera pública, contra-públicos subalternos, publicaciones fuera del libro

Keywords: public sphere, subaltern counterpublics, non-print publications

Mots-clés: sphère publique, contre-publics subalternes, publications hors du livre

\section{AUTORES}

\section{LIONEL RUFFEL}

Université Paris 8 